\title{
Condition Monitoring and Fault Detection of Electric Drives
}

\author{
Christian $\mathrm{Kral}^{1}$ and Thomas G. Habetler ${ }^{2}$ \\ ${ }^{1}$ Austrian Institute of Technology, ${ }^{2}$ Georgia Institute of Technology \\ ${ }^{1}$ Austria, ${ }^{2} U S A$
}

\section{Introduction}

An electric drive consists of an electric machine, which converts electrical power to mechanical power, power electronics to operate the machine and a unit to control the motion of the drive. These are the components of the drive. Parts of each of these components could fail and give rise to specific failure scenarios. The drive types investigated in this chapter are limited to asynchronous induction machine and permanent magnet synchronous machines, since these are the most common machine types in modern electric drive applications. Faults of power electronics are not discussed since most failures lead to the outage of the drive as the power electronics usually show no symptoms before failure.

The task of identifying and classifying drive failures from certain measured quantities is called fault detection. Under some conditions, fault detection may require certain safety protection actions. Example: A turn to turn short circuit in the stator winding of the machine is one example for a safety critical issue. If the short remains for a certain time, parts of the winding will be destroyed. This in turn could cause winding failures that lead to a larger short circuit current which may result in the failure and outage of the entire drive. In this sense, a safety critical issue is a time critical issue. If the failure cannot be detected within a certain time, the drive will be damaged and fails. It is thus highly demanded to accurately detect safety critical faults and to protect the drive (and the application) in this case.

\subsection{Classification of Methods}

Condition monitoring of electric drives is motivated by different intentions. According to these intentions methods can be classified:

- The operating conditions of the drive are stored in a specific format. From the reported state a maintenance action or a warning for the operator can be triggered. Such methods are condition monitoring methods.

- Some state quantities of the drive can be monitored to be fed back to the operating strategy of the drive. Therefore, these classes of methods may be called condition based control methods. An estimated operating temperature of, e.g., the winding of the stator or rotor of the machine can be used to control the machine such way that a certain temperature limit of the windings is not exceeded. 
- A fault indicator can be used to trigger a protection switch to disconnect the drive from the power supply (Farag et al., 1996). In this case the purpose of the condition monitoring method is to protect the drive and the method is called a protection method.

Condition monitoring and fault detection of electric drives are very important tasks in order to maintain the reliability and safety of the drive. Additionally unexpected failures and expensive repair and downtime costs can be avoided or limited this way.

From a technical point of view condition monitoring and fault detection methods can be classified as passive (non-invasive) and active methods.

- Passive methods utilize measured quantities and derive certain fault or condition indicators. These methods are usually applied to mains supplied machines and have to no way of influencing the actual operating condition of the drive.

- Active methods do need any kind of actuator to control the condition of the drive. Such an actuator may be either the inverter of the drive or an additional power electronics device, connected in series to the feeder cables of the machine.

Another classification refers to physical domain for where the measured signals are acquired from.

- Electrical monitoring evaluates only electrical signals such as the currents, voltages, and - in some cases - the mechanical angle between the rotor and stator by means of encoder. For the detection of faults with electrical origin, usually, it is advantageous to evaluate electrical signals.

- Magnetic monitoring assesses the signatures determined from measurement coils. Such coils may either be embedded into the stator slots of the machine or are located externally as Rogowki coils (Henao et al., 2003).

- Vibrational monitoring is based on the evaluation of vibrational acceleration or velocity. Mechanical imbalances and faults are difficult to detect by electrical quantities. It is thus more reasonable to elaborate vibrational signals for the detection of faults with mechanical origin.

- For thermal monitoring the desired temperature can either be measured directly or estimated from state observers or models (Gao et al., 2008a; Kral et al., 2004a).

- Acoustic monitoring is based on the condition specific sound emissions of a drive (Gaylard et al., 1995). The quality of acoustic monitoring, however, is very much dependent on the background noise of the environment, the machine is operated at. It is therefore very difficult to implement such methods in a real industrial environment.

- For mixed physical domain monitoring methods signals from different domains are evaluate and processed.

In this chapter only electrical monitoring methods are investigated and discussed.

\subsection{Structure of Monitoring Methods}

Monitoring methods are usually based on the processing blocks illustrated in Fig. 1. In the first processing block the signals are measured. For currents and voltages usually current and voltage transducers are used. The rotor speed and the rotor angle, respectively, are either retrieved by an encoder or determined from the slotting harmonics of the currents in the frequency or time domain (Hurst \& Habetler 1996; Kral et al., 2006). Alternative 
monitoring methods may measure other quantities such as temperatures, the vibrations of the housing, acoustic emissions or the flux in internal or external coils.

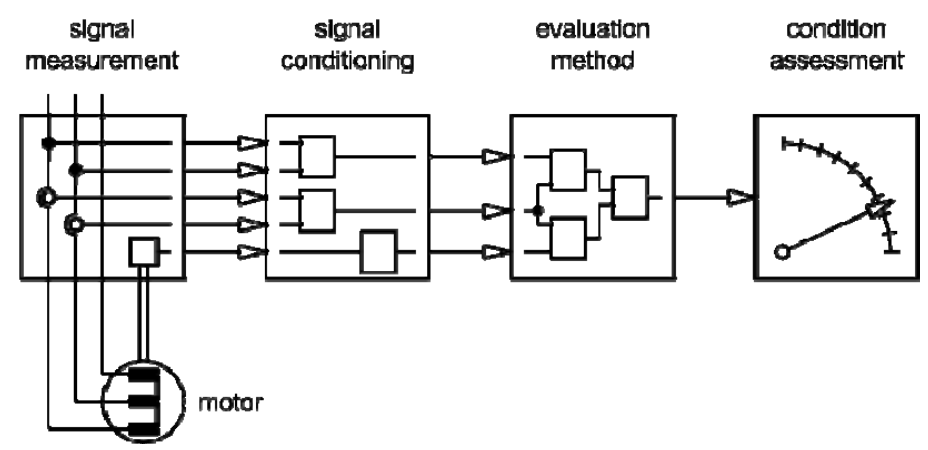

Fig. 1. Block diagram of methods for the detection of machine conditions and faults

Signal conditioning includes some initial processing of the measured quantities. Such processing includes the calculation of the phase voltages and the currents from the measured quantities, depending on whether the connection of the machine is either wye or delta. Additionally, for some methods the space phasors

$$
\begin{gathered}
\underline{v}_{s}=\frac{2}{3}\left(v_{1}+e^{j 2 \pi / 3} v_{2}+e^{-j 2 \pi / 3} v_{3}\right) \\
\underline{i}_{S}=\frac{2}{3}\left(i_{1}+e^{j 2 \pi / 3} i_{2}+e^{-j 2 \pi / 3} i_{3}\right)
\end{gathered}
$$

are determined from the phase voltages $v_{1}, v_{2}, v_{3}$ and phase currents $i_{1}, i_{2}, i_{3}$.

The evaluation method incorporates knowledge on the computation of internal machine quantities or fault signatures from the measured signals. An internal quantity could be, e.g., the stator or rotor temperature of the machine. An example of a fault signature is the harmonic component of the current that indicates an electrical asymmetry of the squirrel cage of an induction machine. In this sense, physical or empirical models or practical findings are applied to indicate the condition of the machine.

If a sound knowledge based on the physical context of certain conditions exists, the assessment of the condition is straight forward. Example: The stator temperature of a machine is estimated by means of condition monitoring technique. The insulation of the stator winding is specified for a specific insulation class and maximum operating temperature. In this context it is clear that if the maximum operating temperature is exceeded, the machine may be damaged. If the stator temperature is integrated into the control of the load of the machine, the set values for the load can be modified such way, that maximum operating temperature is not exceeded. In another application one wants to predict how long the machine can be operated if it is operated above the maximum temperature. Even if the manufacturer of insulation materials provide life cycle curves which assess the total life time as a function of the operating temperature, it may still be difficult to forecast the remaining life time in an application. From this example the reader can suspect that it is very difficult the give a precise answer to the question: How long is it 
possible to operate the machine without failing, considering the given conditions or fault condition. The final question in this context is: when does the operator have to schedule maintenance for the machine. In the literature mostly condition monitoring and fault detection methods are investigated without having the focus on fault assessment (Kral et al., 2003). Only little effort has been spent on the prediction of the remaining life time of machines so far - because the subject is so complex and time and cost intense.

\section{Faults in Permanent Magnet Synchronous Machines}

The high power density and high efficiency of the permanent magnet (PM) machine has led to the use of this machine in applications in which the high reliability is a key feature, such as aerospace/aircraft actuators, automotive auxiliaries and traction, and other industrial and stand-by power generation applications. The switched reluctance motor drives are often used for these applications because of their inherent fault tolerance (Mecrow et al., 1996). While this is true, the switched reluctance machine has a lower power density compared to the PM machine, and therefore is often undesirable. If PM drives are to be considered for these applications, they have to be designed to be very reliable. Redundancy and conservative designs have been used for improving the reliability of these drives against the variety of faults that can occur (Bianchi et al., 1996). As an alternative to these expensive solutions, considerable diagnostic strategies and control schemes have been devised to ensure a fault tolerant drive.

Permanent magnet machines can be divided into two types: permanent magnet synchronous machines (PMSMs) (which have sinusoidal induced stator voltages), and brushless DC machines (BLDCMs) (which have trapezoidal induced stator voltages). PM machines have been very desirable since their torque density and efficiency is higher than any other machine type. However, like all machines, they can fail. Moreover, due to the presence of rotating permanent magnets, damage to the machine can progress even if the stator is disconnected from the line. Fault diagnosis, condition monitoring, and fault tolerant operation of PM machines is very important, if not critical.

\subsection{Detecting Faults in Permanent Magnets}

Rotor magnet defects can be detected by observing the motor current for the same frequencies as given by equation (7) below (Rajagopalan et al., 2004). They can also be detected by estimating the strength of the permanent magnet as demonstrated for PMSMs in (Le Roux et al., 2003). Estimating the instantaneous or RMS back-EMF gives a measure of the flux linkages resulting from the rotor excitation, making it possible to estimate the magnet strength. There are some examples in the literature of estimating the back-EMF, for example in (Wang et al., 2001).

One method for detecting magnet problems is by estimating the d-axis magnet flux linking the stator windings in the synchronous reference frame (Le Roux et al., 2003). This method is derived in the rotor reference frame. The instantaneous value of the d-axis permanent magnet flux linking the stator windings, $\lambda_{d(p m)}^{r}$, is estimated by, (averaging the current over an integer number of fundamental periods), 


$$
\hat{\lambda}_{d(p m)}^{r}=\frac{v_{q s}^{r}-r_{s} i_{q s}^{r}}{\omega_{r}}-L_{d s}^{r} i_{d s}^{r}
$$

In eqn. (3) all quantities are instantaneous values and $i_{d s}^{r}$ is the d-axis stator current, $L_{d s}^{r}$ is the d-axis stator inductance, $v_{q s}^{r}$ is the q-axis stator voltage, $r_{s}$ is the stator resistance, and $\omega_{r}$ is the rotor speed. The average value of $\lambda_{d(p m)}^{r}$ is a direct measure of the magnet strength. In many applications, the rotor angle might not be available to determine the currents and voltages in the rotor rotating reference frame. For these reasons, the estimation is best done in the synchronous reference frame, by averaging $\hat{\lambda}_{d(p m)}^{e}$, which is given by,

$$
\hat{\lambda}_{d(p m)}^{e}=\frac{v_{q s}^{e}-r_{s} i_{q s}^{e}}{\omega_{e}}-L_{d s}^{e} i_{d s}^{e} .
$$

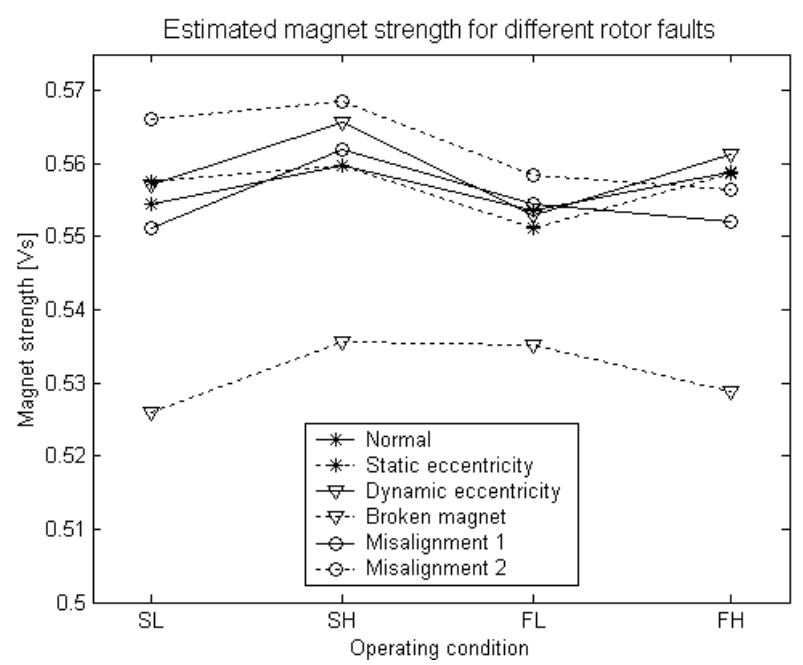

Fig. 2. Estimated magnet strength for different rotor faults at different operating conditions (SL: 640 rpm, 3 Nm; SH: 640 rpm, 6 Nm; FL: 1280 rpm, 4.4 Nm, FH: 1280 rpm, 8.7 Nm)

This method to estimate the magnet strength with (4) was implemented on the measurement data of a normal motor case and all the rotor fault cases. The results of this estimation on these motors operating at different speed and loads are shown in Fig. 2.

For BLDC machines, magnet fault can be found by estimating the mean value of the torque constant, $K_{t}$ (Rajagopalan et al., 2004). For brushless dc machines (BLDC), this is simply the mean value of the added back-EMFs of the two conducting phases in any particular 60degree rotor position region.

The method averages the supply voltage $(\mathrm{V})$ and twice the DC-link current $\left(I_{d c}\right)$ multiplied by the stator resistance $\left(r_{s}\right)$ in every 60-degree region of rotor position during steady-state operation. However, this estimation neglects the variations in stator inductances. The estimation works better when the back-EMF $(E)$ is used directly, but this is not available on a 
physical machine. However, the estimated magnet strength is independent of other faults such as the dynamic and static eccentricities, implying that this estimation could still be used to detect a decrease in the magnet strength. Thus, the estimation of the magnet strength is given by,

$$
\hat{K}=\frac{V-2 r_{s} I_{d c}}{\omega_{r}}=\frac{E}{\omega_{r}} .
$$

\subsection{Detection of Rotor Eccentricity}

Load unbalance, misalignment, improper mounting, and a bent rotor shaft can all cause rotor eccentricities. These eccentricities can be divided into static and dynamic eccentricities (Fig. 3). Static eccentricity is when the rotor is shifted from its normal position at the center of the stator and it rotates in that position. With dynamic eccentricity, the rotor is also shifted from the normal position, but now rotates around the center of the stator. These rotor faults cause problems such as vibration and noise due to unbalanced magnetic pull (UMP). It also causes dynamic problems by adding to torque pulsations.

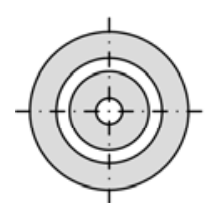

(a)

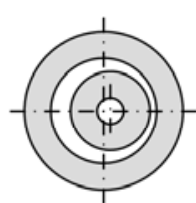

(b)

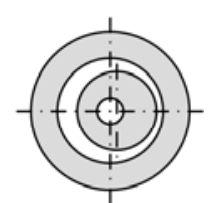

(c)

Fig. 3. (a) centric rotor, (b) rotor with static eccentricity, (c) rotor with dynamic eccentricity

Past research in the detection of rotor eccentricities in induction motors has shown that these faults affect certain frequency components in the stator current which can be monitored for use in diagnosing a fault (see section 3). These frequency components (Cameron et al., 1986) and are given by equation (20) in section 3.4 below. Setting $k, c$, and $o$ in (20) to the appropriate integers yields the frequencies that have to be monitored to detect dynamic eccentricity. Setting $c=0$, yields the principle slot harmonics, which are the frequencies that have to be monitored to detect static eccentricity. However (20) is of little practical use as the knowledge of stator slots is not available and BLDC machines do not have rotor slots.

Dynamic eccentricity in induction motors causes current components at frequencies of, (Dorrell et al., 1997),

$$
f_{d e}=f_{e} \pm \frac{2 m f_{e}}{P}
$$

This equation is the same as equation (18) below, except with slip equal to zero. In (6), $f_{d e}$ is the dynamic eccentricity frequency, $f_{e}$ is the fundamental frequency, and $m$ is any integer. In the presence of dynamic and static eccentricity, current components at the rotating frequency sidebands of $f_{d e}$ can be monitored. This equation can be adapted for use in diagnosis of permanent magnet machines too (Le Roux et al., 2002). In the case of BLDC motor drives, there is no rotor slip. Also, there are no rotor bars or rotor windings and 
therefore there are no rotor slots. This means that $R=0$ and $s=0$ in (6). Thus, the only frequencies that can be used to detect dynamic eccentricity are those given in (6) and integer multiples of the supply frequency harmonics, thus m. $f_{e}$. The only frequencies that are influenced by static eccentricity are the integer multiples of the supply frequency harmonics (setting $R=s=c=0$ ).
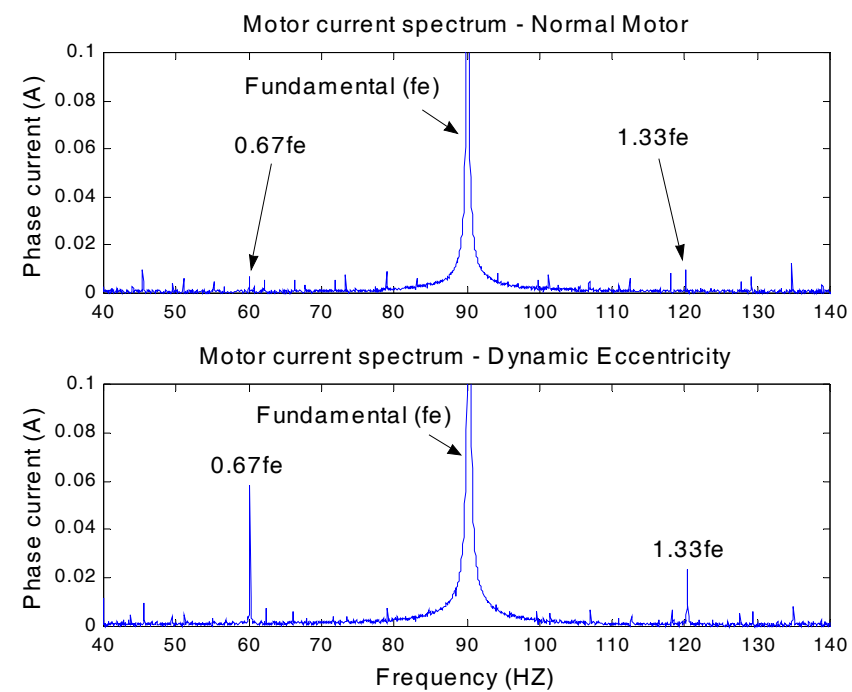

Fig. 4. Comparison of good motor current spectrum to a motor with a dynamic eccentricity

The harmonic spectrum of a good 6-pole PMSM and the same machine with a dynamic eccentricity are shown in Fig. 4. Note the presence of the sidebands of the fundamental at the rotating frequency.

\subsection{Detection of Stator Faults}

The different types of stator turn faults are depicted in Fig. 5. The first stage is small shorts between turns in the same winding. Among the five failure modes, turn-to-turn faults (stator turn fault) have been considered the most challenging one since the other types of failures are usually the consequence of turn faults. Furthermore, turn faults are very difficult to detect at their initial stages.

Conventional turn fault detection schemes merely monitor the negative sequence component of line currents (or the effective negative sequence impedance) and rely on mathematical models for symmetrical induction machines to account for the effect of unbalanced supply voltages on the negative sequence current (Kliman, 1996). However, neglecting inherent asymmetries can lead to misdetection, with catastrophic consequences. The issue of inherent asymmetries can be addressed by using a neural network-based approach (Tallam et al., 2000).

While this technique has been shown to give very good results for line-connected induction machines, it is often not suitable to PM synchronous machine applications since the current controller in the drive attempt to regulate the current to track the reference value. Since the 
current is regulated, the effect of the asymmetry from the fault is now reflected in the motor voltage. For this reason, voltage-based turn fault detection methods have been proposed, but require additional voltage sensors and cables.

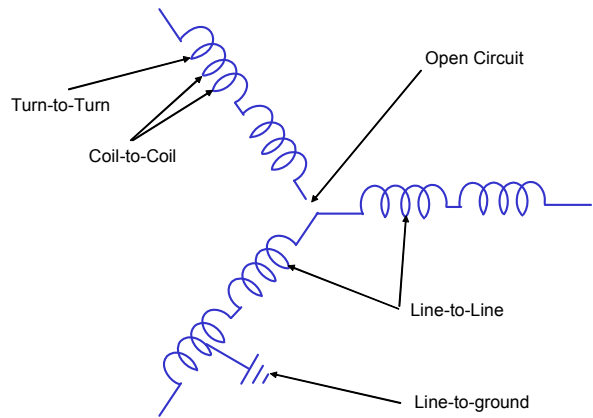

Fig. 5. Possible failure modes in wye-connected stator windings

By modeling a machine with a turn fault, it can be concluded that a bolted turn fault reduces the positive sequence components of the machine impedances and back-emf voltages, while increasing the negative sequence and coupling terms in the impedance matrix at the same time. The positive sequence current slightly increases under a stator turn fault condition in a mains-fed application where the power supply is a fixed voltage source (Lee et al., 2002). In a Current Controlled Voltage Sourced Inverter (CCVSI)-driven application, the inverter controls the line currents so as to follow their references by introducing negative sequence voltage and reducing positive sequence voltage under a stator turn fault condition (Lee et al., 2007). Since the inverter output voltages are produced according to the voltage references that are generated through the current controllers, the variations in the machine parameters will be reflected into the voltage references. This implies that for a given rotating speed and current references (or alternatively torque reference), the presence of a stator turn fault results in a reduced positive sequence component and an increased negative sequence component of the voltage references as compared to a machine without a turn fault. Thus, it can be concluded that the differences in positive and negative sequence components of the voltage references, for a given torque reference and rotating speed, under a stator turn fault and fault-free conditions can indicate the occurrence of a stator turn fault. The voltage references in the rotating and stationary reference frame until fault and no-fault conditions are shown in Fig. 6. 


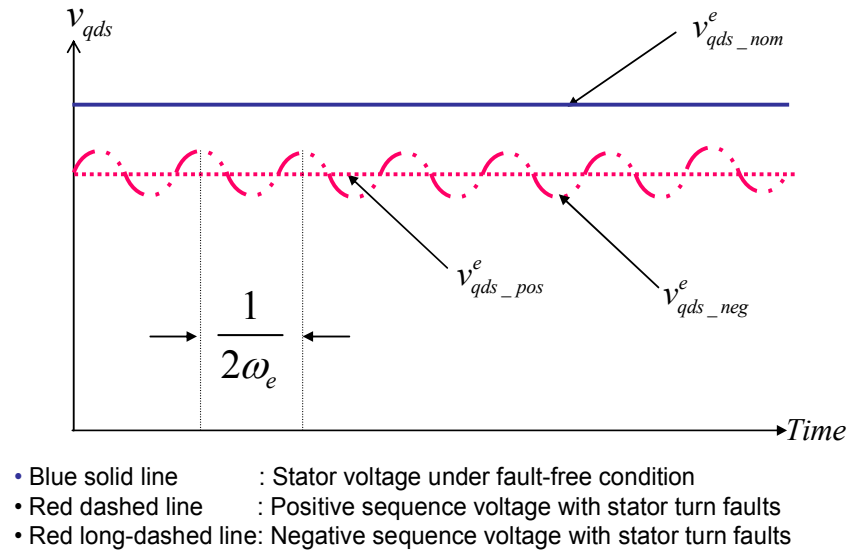

Fig. 6. Voltage references under fault-free and turn fault conditions

\subsection{Fault Tolerant Operation}

Turn faults are particularly problematic in Interior Permanent Magnet Synchronous Machine (IPMSM) drives in safety-critical applications. This is due to the fact that the rotating magnet can often not be stopped when a fault occurs, and therefore the fault current is allowed to flow until catastrophic or dangerous thermal damage is done to the machine. Therefore, PM machines not only require a reliable turn fault detection method, but also imperatively require a proper remedial action that can maintain the drive's uninterrupted operation.

The most desirable characteristic of a remedial action is to maintain the drive's uninterrupted operation without any degradation in the performance characteristics of the drive in the presence of a stator turn fault. Unfortunately, this is very difficult to achieve, and only redundancy-based approaches can solve this difficulty. But these approaches can be justified in specific applications. In transit applications such as traction drives, an uninterrupted operation during a short period of time, even with a limp operation, can prevent injury or death.

A simple stator turn fault-tolerant strategy for IPMSM drives that does not require any hardware modification to the standard drive configuration has been proposed (Lee et al., 2006). This strategy does not result in the complete loss of availability of the drive. Generally, the asymmetry in the stator voltages resulting from a stator turn fault has only a small effect on the overall stator voltage. Therefore the amplitude of the faulty phase voltage is almost the same as that of the complex stator voltage vector $\left(\tilde{v}_{s}^{e}\right)$ in the synchronous rotating reference frame. Consequently, current in the faulted winding is given by,

$$
\left|\tilde{i}_{f}\right| \approx \frac{\left|\tilde{v}_{s}^{e}\right|}{\left|\frac{R_{f}}{\mu}+r_{s}+j \omega_{e}\left[L_{l s}+\mu\left(L_{1}-3 \tilde{L}_{2}\right)\right]\right|} .
$$


Where $R_{f}$ is the resistance of shorted section of the winding, $\mu$ is the fraction of the winding that is shorted, $L_{l s}$ is the leakage inductance, and $L_{1}$ is the average self inductance of the winding, and $L_{2}$ is the first harmonic magnitude of the self inductance. This equation implies that an appropriate selection of $\mathrm{q}$ - and d-axis current combination for a given operating condition can reduce the stator voltage significantly; consequently, a significant reduction in $i_{f}$ is achievable while maintaining the given operating condition.

\subsection{Fault Detection under Non-Stationary Conditions (Rajagopalan et al., 2005)}

Operating conditions of an electric motor usually change rapidly over time. Diagnostics of motor faults in such conditions is a challenging problem due to the need for application of sophisticated signal processing techniques that can process non-stationary signals. While some research has been reported in the detection of faults in induction motors operating under very slowly varying speed and load conditions (Yazici et al., 1999 and Kim et al., 2002), no research has been reported in the diagnosis of faults in motors operating under rapidly varying operating conditions.

The classical technique for characterizing the time evolution of non-stationary signals is the short-time Fourier transform (STFT), a linear time frequency representation (TFR) analysis technique. Though simple and rugged, the STFT still assumes that the non-stationary signal is slowly changing in the chosen time window. This and the choice of window length impair the use of STFT at low frequencies or when the signal is changing very fast dynamically. Beginning with the Wigner-Ville distribution a plethora of quadratic TFR techniques have been introduced in an attempt to improve the time-frequency detail over that achievable with the STFT (Marple et al., 1998). They have been extensively used in the area of mechanical engineering for detection of gear faults.

The use of quadratic TFRs has been presented as a solution for the diagnostics of rotor faults in electric motors operating under non-stationary load and speed conditions. Although the method could be applied to any motor, its application is limited in this discussion to BLDC motors. Four time-frequency representations have been considered - Wigner-Ville distribution (WVD) (Cohen, 1989), Choi-Williams Distribution (CWD) (Choi et al., 1989), and the Zhao-Atlas Marks Distribution (ZAM) (Zaho et al., 1990). The use of time-frequency distributions has proven suitable for detection of rotor faults in electric motors operating under continuous non-stationary conditions. However, the need to provide high frequency resolution along with good cross-term suppression leads to complicated kernels requiring large amounts of processing power.

Some of the commonly used TFRs have been implemented on a DSP platform to study their computational loads. It is observed that quadratic TFRs such as WVD and CWD are computationally more intensive than linear TFRs such as the spectrogram. The quadratic TFRs however provide much better frequency resolution and localization of energy with the ZAM distribution exhibiting the best performance. The CWD in particular is a good tradeoff between the excellent frequency resolution of the WVD and the high cross-term suppression of the ZAM distribution. These distributions also do not depend on the size and type of the window as in the spectrogram. The increased computational load is the price paid if a better frequency resolution and good localization of energy is needed. In spite of the increased complexity involved, the computation time of a CWD is still in the order of a few tens of micro-seconds and hence is amenable to implementation in real-time. This computational time can be further decreased by paralleling several micro-programmed 
systems and using more optimized software routines. The results of Fig. 7 show that the fault frequency magnitudes can be clearly seen even in the case of a time-varying fundamental frequency for the machine.

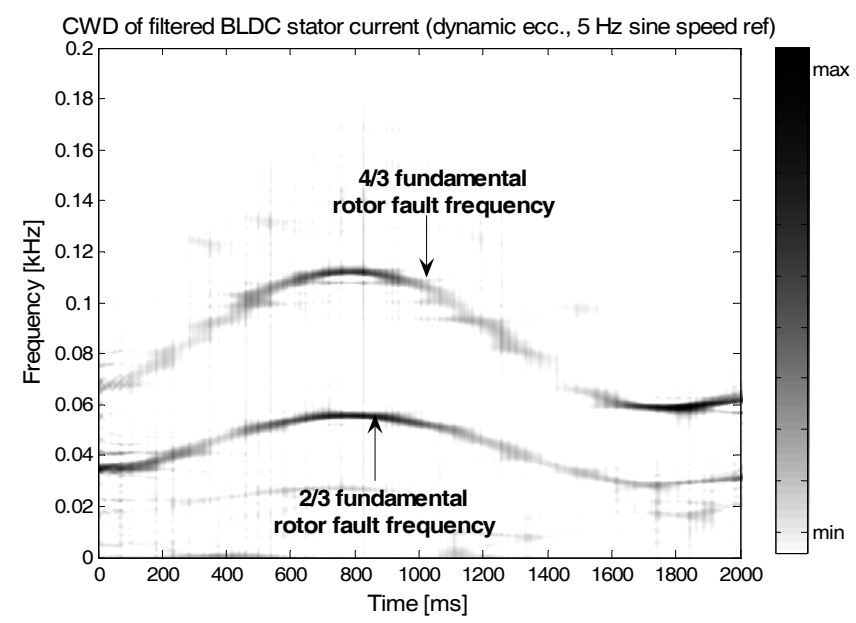

Fig. 7. CWD of a simulated BLDCM rotor fault.

\section{Faults in Induction Machines}

Many fault statistics have been published for induction machines, e.g., (Bell et al., 1985). In these statistics the failure causes are classified. In most statistics the majority of failures are due to bearing and stator faults. Since these statistics mostly refer to industrial applications the statistics may look different for, e.g., railway traction drives. Additionally, any statistic is inherently incomplete, since it very much depends on the boundary conditions and the integrity of the determined data. However, induction machine conditions are usually classified as:

- Stator faults are electrical faults in the stator winding of the machine. Stator faults may be turn to turn faults, interturn faults, phase to phase faults, and phase to ground faults.

- Rotor faults refer to electrical faults of the rotor of an induction machines. Since most machines have a squirrel cage rotor, these faults are also called cage faults.

- The determination of the stator and rotor temperature is of particular interest for the conditional monitoring and control of the machine. The temperature does not directly indicate a fault, but may be an indicator of disadvantageous operating conditions or severe stress to the machine.

- Eccentricity faults are caused by mechanical imbalances, misalignments, bent shafts, or non-uniform air gaps. These eccentricities may be caused by the machine, the mechanical coupling or the mechanical load or any combinations of these. To a certain extent eccentricity faults can be detected by means of electrical measurements over the reaction of magnetic field air gap on the stator currents. 
- Bearing faults are due the failure of one of the bearings of the machine. The causes of failures are manifold and detection of the origin is very difficult. Particularly, the detection of bearing faults by means of electrical signals is a real challenge (Stack et al., 2006).

\subsection{Detection of Stator Faults}

In the case of a fully symmetric stator winding the stator magneto motive force (MMF) can be synthesized as a Fourier series, i.e., a fundamental and higher harmonic waves. A symmetric winding gives rise to a constant magnitude of the fundamental MMF wave. A fault of the stator winding leads to asymmetry of the stator magneto motive force (MMF) caused by the stator winding. This asymmetry causes the magnitude of the stator MMF not be constant any more. In this case the fundamental wave can be decomposed into a forward and backward traveling wave with constant magnitudes. The forward traveling wave is represented by the positive sequence component of the stator current $\underline{i}_{s p}$ and the additional backward traveling wave due to the stator fault is reflected by the negative sequence component of the stator current $\underline{i}_{s n}$. The sequence components are computed from the phase voltages and currents, however.

A negative sequence current could also be caused by a negative sequence voltage which is due to a supply asymmetry. For the reliable detection of stator turn and winding faults it is important not to confuse these faults with supply voltage imbalances. Nevertheless, the measured negative sequence current and voltage component are used to identify stator turn and winding faults (Tallam et al., 2007; Lee et al., 2003). Additionally, inherent winding asymmetries have to be taken into account for stator fault detection techniques.

The negative sequence voltage, $\underline{v}_{s n}$ is coupled to the positive and negative sequence current through impedances,

$$
\underline{v}_{s n}=Z_{s n p} \underline{i}_{s p}+Z_{s n n} \underline{i}_{s n}
$$

In order to compensate inherent winding asymmetries the impedances $Z_{s n p}$ and $Z_{\text {snn }}$ have to be identified. These impedances are (slightly) dependent on the operating conditions of the machine. The identification of the impedances may therefore be performed by means of neural networks or functional approximations (Tallam et al., 2000). This way supply voltage imbalances and inherent winding asymmetries are properly taken into account. For less sensitive methods, the impedances are assumed to be constant quantities (Kral et al., 2007). After a learning stage, where impedances are identified, the fault detection method can be applied in the regular operation of the machine.

For the identification of the impedances $Z_{s n p}$ and $Z_{s n n}$ a negative sequence voltage is required, since a symmetric voltage supply does not give rise to negative sequence currents in case of a symmetric machine. The negative sequence voltage can be generated by means of a single phase ohmic resistor which leads to asymmetric line to line voltages. If it is not possible to introduce a negative sequence voltage, the impedances cannot be indentified except for inherent voltage asymmetries caused by asymmetric loads.

From the measured positive and negative sequence current, the computed negative sequence voltage (8) can be compared with the measured negative sequence voltage. 
Alternatively the computed negative sequence current according to (8), incorporating the measured positive sequence current and the measured negative sequence voltage, can be compared with the measured negative sequence current. Any deviation of the computed from the measured value then indicates a stator fault.

In closed loop inverters the identification of the negative sequence component could be contained in the machine voltages and currents (Tallam et al., 2003). It is thus important to take both, the negative sequence voltage and current for the fault detection into account. Nevertheless, the artificially generation of negative sequence currents for the determination of the impedances applied in (8) is much easier since the reference currents can be superimposed with a negative sequence reference quantity.

An alternative method for the detection of stator faults in inverter fed drives is based on the statistical evaluation of the switching behavior of the current controller which is caused by an electrical asymmetry of the stator winding (Wolbank et al., 2003). The advantage of this method is that it easy to implement on an existing dive, since statistical evaluation has to be implemented by means of additional software routines.

(a)

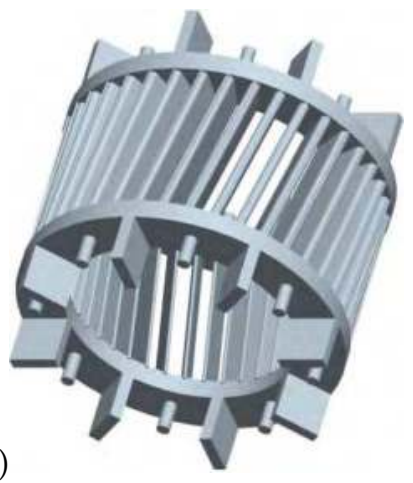

(b)

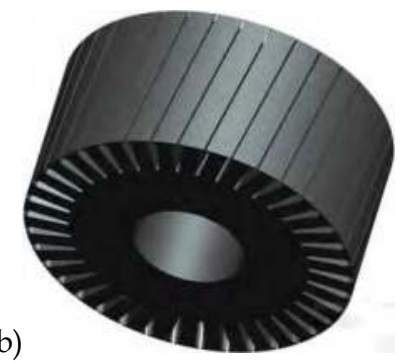

Fig. 8. The squirrel cage rotor of an induction machine consists of (a) rotor bars and end rings and (b) sheet iron

\subsection{Detecting Faults in the Squirrel Cage}

The squirrel cage of induction machine consists of $R$ rotor bars and end rings on both ends which are placed in the sheet iron of the rotor as depicted in Fig. 8. The bars and end rings of small machines are usually die casted of aluminum or copper. For larger machines, the copper bars are insulated and manually fitted into the sheet iron. In this case the bars and end rings are either welded or hard-soldered.

In the symmetric cage of a squirrel cage induction machine the root mean square (RMS) values of the bar currents are equal - except for inherent asymmetries. Therefore, also end ring currents on both sides are equal. In case of a faulty rotor bar, which is physically reflected in an increase of the respective bar resistance, the current flow of this bar is diminished. 


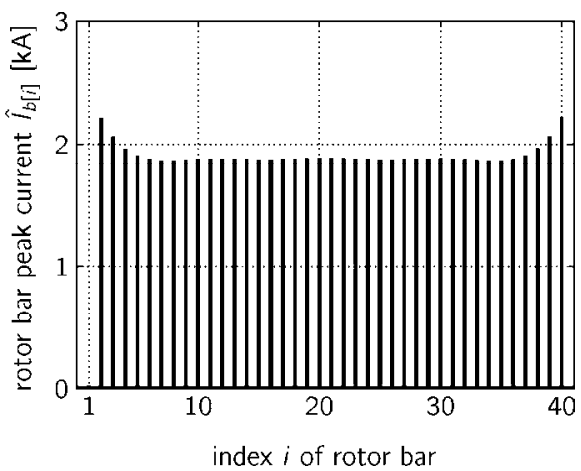

Fig. 9. RMS values of rotor bar currents for the case of one broken rotor bar (index 1); results refer to an $18.5 \mathrm{~kW}$ induction machine with 40 rotor bars

In Fig. 9 the RMS rotor bar currents of a squirrel cage with one broken rotor bar are depicted. Since bar number 1 is broken, the respective current is zero. Therefore, the bars adjacent to the fault location have to carry higher RMS bar currents than the rest of bars. The increased currents lead to an increased thermal stress of the respective bars. Due to this phenomenon the adjacent bars could also fail. This in turn leads to the spreading out of the fault from an initial fault location. Over time, the fault condition of the rotor gets worse and worse until the machine fails.

In a real machine a faulty bar leads to an additional phenomenon. Since the rotor bars are usually not insulated from the sheet iron, interbar currents occur. The original bar current is thus diverted to the iron parts of the rotor which in turn damages the sheets.

Apart from broken rotor bars, broken end ring or broken junctions of the bars and end ring segments may give also rise to an electrical asymmetry of the rotor. The entirety of these faults is also called electrical rotor asymmetries. These faults cause a distortion of the rotor MMF which can be interpreted as a forward and a backward traveling rotor MMF wave with respect to the rotor reference frame. The backward traveling rotor MMF wave induces voltages in the stator winding at the so called lower side band frequency

$$
f_{\text {lsb }}^{r}=(1-2 s) f_{e},
$$

where $f_{e}$ is the fundamental stator supply frequency and $s$ represents slip. The superscript $r$ indicates that the frequency refers to a rotor fault. The interaction of this harmonic component with the flux causes a double slip frequency

$$
f_{t}^{r}=2 s f_{e}
$$

torque pulsation. Due to the finite inertia of the drive, rotor speed pulsations occur at the same frequency. The speed pulsations then induce additional side band harmonics in the stator currents, i.e.,

$$
f_{\mathrm{lsb}[m]}^{r}=(1-2 m s) f_{e},
$$




$$
f_{\mathrm{usb}[m]}^{r}=(1+2 m s) f_{e} .
$$

where $m$ is a positive integer order number. The index usb abbreviates the term upper side band, however. The entirety of current harmonics is also reflected in low frequency torque and instantaneous power pulsations at

$$
f_{t[m]}^{r}=2 m s f_{e} .
$$

A typical stator current Fourier spectrum for steady state operation of an induction machine is depicted in Fig. 10. The equidistant displaced lower and upper side band currents are clearly arising in this figure.

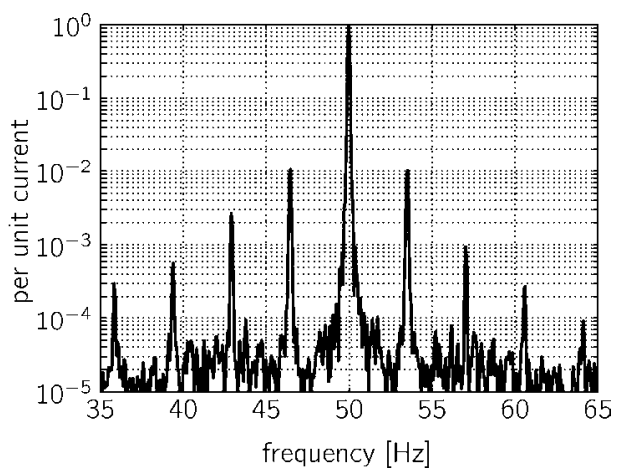

Fig. 10. Fourier spectrum of a per unit stator current during steady state operation; results refer to a $18.5 \mathrm{~kW}$ induction machine with one broken rotor bar out of 40 bars

A rotor fault can only be detected when the rotor currents lead to sufficient reactions on the air gap field. The magnitudes of the side band currents of stator current are proportional to load torque in steady state. The magnitudes of side band harmonics with low ordinal numbers $m$ are larger than the magnitudes with higher ordinal numbers. When the mechanical load of the machine is relieved, slip decreases and the magnitudes of the side band currents decrease as well. In this case the side band harmonics merge with the fundamental according to (11) and (12). Therefore, a rotor fault cannot be detected when the machine is mechanically unloaded in steady state. For the reliable detection of rotor faults a minimum load torque of approximately $30 \%$ of the nominal torque is required.

The magnitudes of the lower and upper side band harmonics are also influenced by the total inertia of the drive. A large inertia leads to a dominant magnitude of the lower side band harmonic component (9) in the stator current, whereas a low inertia gives rise to a decreased lower side band and an increased higher side band component (Kral et al., 2008a).

Most rotor fault detection methods are based on the evaluation of one or more stator current signatures and are thus called current signature analysis (CSA) methods. For steady state operating conditions a conventional Fourier analysis can be used to identify electrical rotor asymmetries. For such applications, it is important to determine the magnitudes of the respective current harmonics with high precision. Since low frequency torque fluctuations 
can also induce current sidebands as depicted in Fig. 10, it is important to exactly track the fault specific frequency components so that they do not get confused with load specific harmonics (Kral et al., 2005). From the magnitudes of the side band harmonics the extent of the fault can be estimated according to formulas presented in the literature, e.g., (Thomson \& Ranking 1987; Bellini et al., 2000; Culbert \& Rhodes 2007).

During transient operating conditions, load torque and thus slip are not constant. A conventional Fourier analysis is therefore not applicable in this case. The problem of time varying load torque can either be solved by means of compensating the modeled load torque (Schoen et al., 1995) or by mathematical transformations and algorithms (Wu et al., 2005). Other approaches use a short time Fourier analysis or multiple signal classification (MUSIC) algorithms to overcome the problem of identification of the non-stationary fault signatures (Benbouzid \& Kliman 2003). The fault detection under transient operating conditions can also be performed by means of wavelet transforms (Antonino-Daviu et al., 2006).

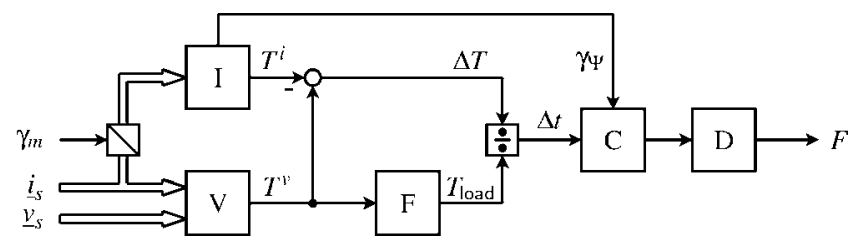

Fig. 11. Scheme of the Vienna Monitoring Method: $\mathrm{V}=$ voltage model, $\mathrm{I}=$ current model; $\mathrm{F}=$ low pass filter for determining the (average) load torque from the torque of the voltage model, $\mathrm{C}=$ spatial data clustering technique, $\mathrm{D}=$ discrete Fourier analysis

Apart from these methods, electrical rotor asymmetries can be detected by means of the Vienna Monitoring Method (VMM). A scheme of this method is depicted in Fig. 11. This method is a model based approach which compares the torque signals $T^{v}$ and $T^{i}$ of a voltage and current model of the machine, resptively; the superscript indicates the model reference. Both these mathematical models are the models of a symmetrical machine. The voltage model is based on the stator voltage equation in the stator reference frame, whereas the current model relies on the rotor voltage in the rotor reference frame. The input quantities of the voltage model are the stator voltage and current space phasor (1) and (2). Since the current model is utilized in the rotor reference frame the stator current space phasor has to be transformed by means of the mechanical angle $\gamma_{m}$ - which is the electrical angle of the rotor with respect to the stator.

Applied to a fully symmetrical machine each model calculates the same torque and thus the torque difference

$$
\Delta T=T^{v}-T^{i}
$$

is zero. In case of a rotor fault, both models will calculate a double slip harmonic torque oscillation - as well as higher harmonics which are, however, not taken into account in the VMM. The double slip harmonic torque oscillations computed by the voltage and current model show different magnitudes and phase angles, since both models have a different model structure and different input signals. It turned out that the magnitude of the torque 
difference is directly proportional to the fault extent and the load torque (Wieser et al., 1999). If the torque difference is divided by the estimated load torque - which is determined from, e.g., the voltage model - the relative torque difference is obtained,

$$
\Delta t=\frac{\Delta T}{T_{\text {load }}} .
$$

The magnitude of the double slip frequency component of $\Delta t$ is independent of the load torque and thus a measure for the electrical asymmetry of the rotor. Nevertheless, the frequency of the relative torque difference is depending on slip. In order to eliminate the time dependency of the relative torque difference, a spatial data clustering technique is applied. This technique investigates the relative torque difference versus the angle of the rotor flux space phasor, $\gamma_{\Psi}$, which is determined by the current model in Fig. 11. Since the rotor flux with respect to the rotor reference frame rotates with slip frequency, the double slip frequency oscillation of the relative torque difference is mapped into a second harmonic component with respect to the rotor circumference. A clustering technique is used to average the wave forms of the obtained second harmonic signal. For this purpose, that rotor circumference is subdivided into $n$ data segments. The data value of each segment is then derived by applying a recursive averaging algorithm. The data values represent an averaged and discretized wave of the second harmonic torque difference. After a certain measurement period a discrete Fourier analysis is applied to the data values. The magnitude of the second harmonic then represents the averaged magnitude of the double slip frequency component of the relative torque difference - which in turn serves as fault indicator for the VMM (Kral et al., 2008a).

A great advantage of the VMM is that it reliably detects rotor faults under almost any operation and boundary conditions. The VMM works

- independent of the load torque of the machine,

- under stationary and transient load conditions,

- under varying load and speed conditions,

- independent of the inertia of the drive,

- for mains supplied and inverter fed machines, independent of the applied control technique and structure.

\subsection{Monitoring of Stator and Rotor Temperature}

The stator temperature of a machine can be measured by means of sensors which are embedded in the winding, the winding heads or the sheet iron of the stator. This is a state of the art measurement technology. Measuring the rotor temperatures is much more difficult since the rotor is spinning and measuring lines can thus not be used. Even if there exist radio frequency (RF) transmission sensors such technology is almost impossible to be implemented in an industrial environment, because the machine to be monitored has to be dismounted and modified - which is highly undesired.

In some applications it may be undesired to even measure the stator temperatures. In this case it is then required to estimate the temperatures of the stator and rotor, respectively. Neither stator nor rotor temperature are precise terms, since temperature is a local quantity. Both the stator and the rotor have specific temperature distributions, depending on the 
actual operating conditions. It is for the symmetrical machine (and supply), however, useful to assume homogenous or averaged temperatures, for the conductors in the stator slots, each winding head as well as each rotor bar and both end rings. By means of a lumped parameter thermal model of the machine, these temperatures can be determined (Kral et al., $2008 b)$ - even online. In order to parameterize such a model all geometric details of the stator, rotor, housing and cooling concept have to be known and modeled. A complex lumped parameter model is thus not applicable in practice if the only little is known about the machine.

For practical applications simplified lumped thermal parameter models can be used (Gao et al., 2008b). These models usually employ only a couple thermal time constants. The thermal time constants have to be determined during an identification test or are computed or measured in advance before the machine is put into operation. A lumped parameter thermal model can also be combined with any other resistance estimation method to a hybrid model (Kral et al., 2004a).

In practice, only the average temperature of the stator winding can be estimated. The average stator winding temperature increase is determined by estimating the stator resistance, considering the temperature dependence of the conductor according to,

$$
R=R_{\text {ref }}\left(1+\alpha_{\text {ref }}\left(T-T_{\text {ref }}\right)\right),
$$

where $R_{\text {ref }}$ is the resistance at temperature $T_{\text {ref }}$, and $\alpha_{\text {ref }}$ is the linear temperature coefficient at the reference temperature. In this equation $T$ is the actual temperature and $R$ is the respective actual resistance. One class of methods determines the average stator winding temperature by means of a direct current (DC) bias. Since a DC current does not cause any voltage drop across the stator inductance, the DC voltage represents the voltage drop across the stator resistance only. For symmetric machines it can be assumed that the winding temperatures are equal in all three phases. Therefore, the DC bias is injected only in one phase. For mains fed induction machines the bias could be applied by means of different devices: A resistor in parallel with a diode can be used to cause a voltage drop across this element which is different with respect to the positive and the negative half-wave (Lee \& Habetler, 2003b). Other proposals provide the controlled bias by a soft starter, giving rise to a similar effect (Zhang et at., 2008), or use a zero sequence voltage to estimate the stator resistance of the machine (Jacobina et al., 2000).

Since the estimation of resistances is required for the tuning the control of inverter drives, such methods are often integrated into the digital signal processing (DSP) software of the drive. For this class of applications rotor and stator resistances may be focus of interest. In this context observers (Jeon et al., 2002), models (Gao et al., 2008a) and neural networks (Karanayil et al., 2007) are applied. In variable speed drives also signal injection methods can be used to determine the resistances since the inverter can be seen as active voltage source (Wu \& Gao, 2006).

\subsection{Detection of Rotor Eccentricity}

Rotor eccentricities are usually classified by the terms static and dynamic eccentricity. A visualization of these classes is depicted in Fig. 3. For static eccentricity the axis of rotation of the rotor is displaced from geometric center of the stator. This eccentricity mode can be 
caused by a misalignment of the bearings, the end shields or stator ovality. Since the air gap and the air gap field are non-uniform in this case a so called unbalanced magnetic pull arises. This pull acts in the direction of the minimum air gap. In the case of dynamic eccentricity the axis of rotation of rotor is aligned with center of the stator, but the axis of rotation is displaced from the rotor center. Dynamic eccentricity may be caused by a bent shaft, mechanical resonances, bearing wear and static eccentricity. An unbalanced magnetic pull is also present in this case (Dorrell 1996). In practice always mixed modes of eccentricity occur (Faiz \& Ojaghi 2008).

Mixed static and dynamic eccentricity gives rise to harmonic components with frequencies

$$
f_{i[m]}^{e}=f_{e}\left(1 \pm m \frac{1-s}{P}\right)
$$

in the stator currents, where $P$ is the number of pole pairs and superscript $e$ indicates the reference to eccentricity related components and $m \in[1,2,3, \ldots]$ is the ordinal number. Due to the interaction of current and flux, power and torque specific components arise at

$$
f_{t[m]}^{e}=f_{e} m \frac{1-s}{P}
$$

The slotting of the rotor also gives rise to additional frequencies

$$
f_{i R[m]}^{e}=f_{e}\left[(m R \pm c) \frac{1-s}{P} \pm o\right]
$$

in the current, where $c \in[0,1]$ indicates static (zero) or dynamic (one) eccentricity, and $o$ is an odd integer number, $o \in[1,3,5, \ldots]$.

For stationary operated induction machines, supplied by the mains, the eccentricity related harmonic components (17)) or (19)) can be determined by means of a conventional Fourier analysis (Thomson \& Fenger 2001). Oscillating load effects require different approaches since a Fourier analysis is not applicable any more. An alternative method utilizes the negative sequence fault components of the stator current space phasor which is independent of the actual loading of the machine (Wu et al., 2007).

Another approach strictly avoids time domain frequency analysis and is based on the evaluation of (18) applied to instantaneous power (Kral et al., 2004b). A scheme of this method is depicted in Fig. 12. In order to evaluate a quantity independent of the actual rating of the machine, instantaneous power is divided by a reference power, which is, e.g., equal to the nominal power of the machine. A band pass filter extracts the frequency components (18) and a phase locked loop (PLL) is used to track the filtered signal. Since power is a real quantity, a Hilbert transform is applied to generate a complex phasor. The angle $\gamma$ of the quantity associated to the output of the Hilbert transform is then used to employ a data clustering technique similar to that one used for the Vienna Monitoring Method in subsection 3.2. The data clustering averages the output of the filter in a spatial domain to eliminate any frequencies other than the fault frequency. 


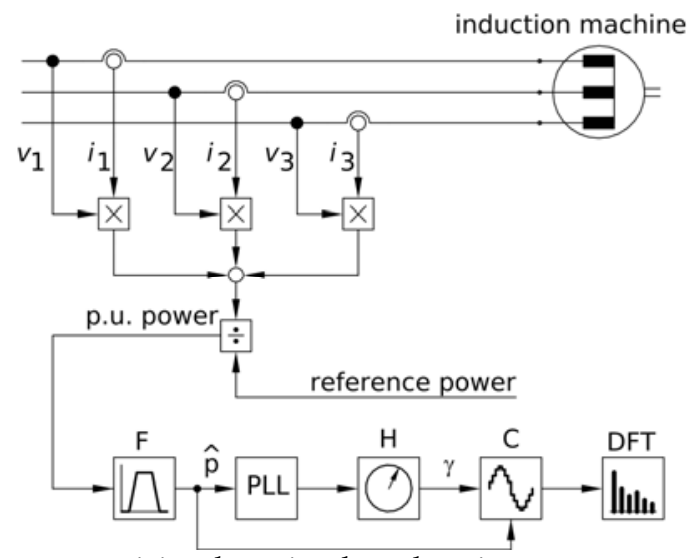

Fig. 12. Method for the eccentricity detection based on instantaneous power; $\mathrm{F}=$ band pass filter, $\mathrm{PLL}=$ phase locked loop, $\mathrm{H}=$ Hilbert transform, $\mathrm{C}=$ clustering technique, $\mathrm{DFT}=$ discrete Fourier analysis

Eccentricities have mechanical origins and therefore fault detection based on vibration signals leads to more direct - without the interaction of the magnetic field and the reaction on the stator currents - and thus more significant signatures. A fault signature according to (17) and (18) may also be caused by a mechanical mass imbalance of the rotating parts. This case was investigated in (Kral et al., 2004c) with a non-rigid mounting of the machine. It turned out that it is difficult to detect a mechanical problem by means of current signatures whereas vibrational signatures very clearly indicate the issue. The result of this investigation thus shows that the detection of mechanical problems by means of electrical signals is limited.

\section{Conclusions}

In this chapter state of the art fault detection methods for permanent magnet and induction machines are presented. The discussed methods rely on the evaluation of measured voltages, currents and speed, respectively. Each kind of fault gives rise to a specific fault pattern in either of the measured quantities. Advanced signal processing techniques and neural network methods are used to isolate and assess the fault severity accordingly.

The field of rotating electric machine monitoring and diagnostics has seen major advancements in the two decades. As a result of this, simple motor protection devices will soon be replaced with sophisticated monitoring devices which will provide early indication of impeding faults. The technology described in this chapter can be used to greatly improve factory and process reliability and availability by reducing unscheduled downtime. The potential cost savings are enormous. All of this can be achieved at little or no cost since all the technology here relies only on the use of data from sensors that are all ready installed. Virtually everything described here can be implemented with only software changes to existing microprocessor-based protection relays. 
The future will be even more exciting as advances are made in sensorless monitoring of mechanical systems driven by electrical machines, motor bearings, and a wide variety of motor types in a myriad of applications.

\section{References}

Antonino-Daviu, J. A.; Riera-Guasp, M.; Folch, J. R. \& Palomares, M. P. M. (2006). Validation of a new method for the diagnosis of rotor bar failures via wavelet transform in industrial induction machines, IEEE Transactions on Industry Applications, vol. 42, no. 4, pp. 990996.

Bellini, A.; Fillipetti, F.; Franceschini, G.; Tassoni, C.; Passaglia, R.; Saottini, M. \& Tontini, G. (2000). ENELs Experience with On-Line Diagnosis of Large Induction Motors Cage Failures, Conference Record of the IEEE Industry Application Conference, IAS.

Benbouzid, M. E. H. \& Kliman, G. B. (2003). What stator current processing-based technique to use for induction motor rotor faults diagnosis?, IEEE Transactions on Energy Conversion, vol. 18 , no. 2 , pp. 238-244.

Bianchi, N., S. Bolognani and M. Zigliotto, (1996). Analysis of PM Synchronous Motor Drive Failures during Flux Weakening Operation, in Proceedings of the 27th Annual IEEE Power Electronics Specialist Conference - PESC96, Baveno, Italy, 23-27, pp. 1542-1548.

J.M. Cameron, W.T. Thomson and A.B. Dow. (1986). Vibration and Current Monitoring for Detecting Airgap Eccentricity in Large Induction Motors, IEE Proceedings, vol. 133, pt. B, no.3, pp. 155-163.

H. I. Choi and W. J. Williams, (1989). Improved time-frequency representation of multicomponent signals using exponential kernels, IEEE Trans. on Acoustics, Speech, and Signal Processing, vol. 37, no. 6, pp. 862-871.

Cohen, L. (1989). Time-frequency distributions - A review, Proceedings of the IEEE, vol. 77, no. 7, , pp. 941-981.

Culbert, I. M. \& Rhodes, W. (2007). Using Current Signature Analysis Technology to Reliably Detect Cage Winding Defects in Squirrel-Cage Induction Motors, IEEE Transactions on Industry Applications vol. 43, no. 2, pp. 422-428.

Dorrell, D. G. (1996). Calculation of Unbalanced Magnetic Pull in Small Cage Induction Motors with Scewed Rotors and Dynamic Rotor Eccentricity, IEEE Transactions on Energy Conversion, pp. 483-488.

Dorrell, D.G., Thomson, W.T., and Roach, S. (1997). Analysis of Airgap Flux, Current, and Vibration Signals as a Function of the Combination of Static and Dynamic Airgap Eccentricity in 3-Phase Induction Motors, IEEE Transactions on Industry Applications, vol. 33, no. 1, (January/February) pp. 24-34.

Faiz, J. \& Ojaghi, M. (2009). Different indexes for eccentricity faults diagnosis in three-phase squirrel-cage induction motors: A review, Mechatronics, vol. 19, no. 1, pp. 2 - 13.

Farag, S. F.; Bartheld, R. G. \& Habetler, T. (1996). An Integrated on-Line Motor Protection System, IEEE Industry Applications Magazine, vol. 2, no. 2, pp. 21-26.

Gao, Z.; Habetler, T. G.; Harley, R. G. \& Colby, R. S. (2008a). A Sensorless Rotor Temperature Estimator for Induction Machines Based on a Current Harmonic Spectral Estimation Scheme, IEEE Transactions on Industrial Electronics, vol. 55, no. 1, pp. 407-416. 
Gao, Z.; Colby, R. S.; Habetler, T. G. \& Harley, R. G. (2008b). A Model Reduction Perspective on Thermal Models for Induction Machine Overload Relays, IEEE Transactions on Industrial Electronics, vol. 55, no. 10, (October 2008) pp. 3525-3534.

Gaylard, A.; Meyer, A. \& Landy, C. (1995). Acoustic evaluation of faults in electrical machines, Seventh International Conference on Electrical Machines and Drives, IEE (Conf. Publ. No. 412), pp. 147-150.

Henao, H.; Demian, C. \& Capolino, G. (2003). A frequency-domain detection of stator winding faults in induction machines using an external flux sensor, IEEE Transactions on Industry Applications, vol. 39, pp. 1272-1279.

Hurst, K. D. \& Habetler, T. G. (1996). Sensorless speed measurement using current harmonic spectral estimation in induction machine drives, IEEE Transactions on Power Electronics, vol. 11, no. 1, pp. 66-73.

Jacobina, C. B.; Filho, J. E. C. \& Lima, A. M. (2000). On-line estimation of the stator resistance of induction machines based on zero-sequence model, IEEE Transactions on Power Electronics, vol. 15, no. 2, pp. 346-353.

Jeon, S. H.; Oh, K. K. \& Choi, J. Y. (2002). Flux observer with online tuning of stator and rotor resistances for induction motors, IEEE Transactions on Industrial Electronics, vol. 49, no. 3, pp. 653-664.

Karanayil, B.; Rahman, M. F. \& Grantham, C. (2007). Online Stator and Rotor Resistance Estimation Scheme Using Artificial Neural Networks for Vector Controlled Speed Sensorless Induction Motor Drive, IEEE Transactions on Industrial Electronics, vol. 54, no. 1, pp. 167-176.

Kim, K. and Parlos, A. G. (2002). Induction motor fault diagnosis based on neuropredictors and wavelet signal processing, IEEE/ASME Trans. Mechatronics, vol. 7, no. 2, , pp. 201-219.

Kliman, G.B., W.J. Premerlani, R.A. Koegl, D. Hoeweler, A New Approach to On-Line Turn Fault Detection in ac Motors, Conference Record of the IEEE-IAS Annual Meeting, 1996, pp, pp. 687-693.

Kral, C.; Habetler, T. G.; Harley, R. G.; Pirker, F.; Pascoli, G.; Oberguggenberger, H. \& Fenz, C. J. M. (2003). A Comparison of Rotor Fault Detection Techniques with Respect to the Assessment of Fault Severity, Symposium on Diagnostics for Electric Machines, Power Electronics and Drives, SDEMPED, pp. 265-270.

Kral, C.; Habetler, T. G.; Harley, R. G.; Pirker, F.; Pascoli, G.; Oberguggenberger, H. \& Fenz, C. (2004a). Rotor Temperature Estimation of Squirrel-Cage Induction Motors by Means of a Combined Scheme of Parameter Estimation and a Thermal Equivalent Model, IEEE Transactions on Industry Applications, vol. 40, no. 4, pp, pp. 1049-1057, ISSN 0093-9994

Kral, C.; Habetler, T. G. \& Harley, R. G. (2004b). Detection of Mechanical Imbalances of Induction Machines Without Spectral Analysis of Time-Domain Signals, IEEE Transactions on Industry Applications, vol. 40, no. 4, pp. 1101-1105, ISSN 0093-9994

Kral, C.; Fenz, C.; Plainer, M.; Pirker, F. \& Pascoli, G. (2004c). Mechanical Imbalances---Test Bed, Measurement, Detection Technique, International Conference on Electric Machines, ICEM.

Kral, C.; Kapeller, H.; Pirker, F. \& Pascoli, G. (2005). Discrimination of Rotor Faults and Low Frequency Load Torque Modulations of Squirrel Cage Induction Machines by Means of the Vienna Monitoring Method, IEEE 36th Annual Power Electronics Specialists Conference, PESC, Recife, Brazil, pp. 2861-2866. 
Kral, C.; Gragger, J.; Pirker, F. \& Pascoli, G. (2006). Sensorless Rotor Position Estimation through Current Signature Analysis Based on Rotor Saliency Harmonics, International Symposium on Power Electronics, Electrical Drives, Automation and Motion, SPEEDAM 2006.

Kral, C.; Kapeller, H. \& Pirker, F. (2007). A Stator and Rotor Fault Detection Technique for Induction Machines in Traction Applications for Electric or Hybrid Electric Vehicles, The World Electric Vehicle Association Journal, WEVA, vol. 1, pp. 184-189.

Kral, C.; Pirker, F. \& Pascoli, G. (2008a). The Impact of Inertia on Rotor Fault Effects - Theoretical Aspects of the Vienna Monitoring Method, IEEE Transactions on power electronics, vol. 23, no. 4, pp. 2136-2142.

Kral, C.; Haumer, A. \& Bäuml, T. (2008b). Thermal Model and Behavior of a Totally-EnclosedWater-Cooled Squirrel-Cage Induction Machine for Traction Applications, IEEE Transactions on Industrial Electronics, Vol. 55, No. 10, October 2008 3555, vol. 55, no. 10, pp. 3555-3565.

Le Roux, W., R.G. Harley and T.G. Habetler, (2002). Rotor Fault Analysis of a Permanent Magnet Synchronous Machine, Proceedings of the 15th International Conference on Electrical Machine (ICEM02) on CD, Brugge, Belgium, pp. 25-28.

Le Roux, W., R.G. Harley and T.G. Habetler, (2003). Detecting Rotor Faults in Permanent Magnet Synchronous Machines, Proceedings of the 4th International Symposium on Diagnostics for Electric Machines, Power Electronics and Drives on CD, Atlanta, Georgia, pp. 24-26.

Lee, S.-B., Habetler, T.G.; Harley, R.G.; and Gritter, D.J. (2002). "An evaluation of model-based stator resistance estimation for induction motor stator winding temperature," IEEE Transactions on Energy Conversion, vol. 17, no. 1, pp. 7-15.

Lee, S. B.; Tallam, R. M. \& Habetler, T. G. (2003a). A robust, on-line turn-fault detection technique for induction machines based on monitoring the sequence component impedance matrix, IEEE Transactions on Power Electronics, Vol. 18, No. 3, pp. 865-872.

Lee, S. \& Habetler, T. G. (2003b). An online stator winding resistance estimation technique for temperature monitoring of line-connected induction machines, IEEE Transactions on Industry Applications, vol. 39, no. 3, pp. 685-694.

Lee, Y.-K.; Habetler, T.G. (2006). A Stator Turn Fault Tolerant Strategy for Induction Motor Drives in Safety Critical Applications, IEEE Power Electronics Specialists Conference, pp. $1-7$.

S. L. Marple Jr. (1998). Time-frequency signal analysis: issues and alternative methods, in Proceedings of the IEEE-SP International Symposium on Time-Frequency and Time-Scale Analysis, pp. 329-332.

B.C. Mecrow, A.G. Jack, J.A. Haylock and J. Coles, (1996). Fault-Tolerant Permanent Magnet Machine Drives, IEE Proceedings-Electric Power Applications, Vol. 143, No. 6, pp. 437-442.

Pal, S.K. (1991). Design Criteria for Brushless DC Motors with Hollow Rotor of Samarium Cobalt for Applications above 25000 RPM in Vacuum, Proceedings of the 5th International Conference on Electrical Machines and Drives, London, UK, pp. 115-120.

Rajagopalan, S., Le Roux, W., Habetler, T.G. and Harley, R.G. (2004). Diagnosis of potential rotor faults in brushless DC machines, Second International Conference on Power Electronics, Machines and Drives (PEMD 2004). vol. 2, pp. 668 - 673. 
Rajagopalan, S.; Restrepo, J.A.; Aller, J.M.; Habetler, T.G.; Harley, R.G. (2005); Selecting timefrequency representations for detecting rotor faults in BLDC motors operating under rapidly varying operating conditions, Annual Conference of the IEEE Industrial Electronics Society, IECON, pp. 6-10, 2005, (Nov 2005) pp. 2579 - 2584.

Stack, J. R.; Habetler, T. G. \& Harley, R. G. (2006), 'Fault-signature modeling and detection of inner-race bearing faults', IEEE Transactions on Industry Applications 42(1), 61-68.

Tallam, R. M.; Habetler, T. G.; Harley, R. G.; Gritter, D. J. \& Burton, B. H. (2000). Neural Network Based On-Line Stator Winding Turn Fault Detection for Induction Motors, Conference Record of the IEEE Industry Application Conference, IAS.

Tallam, R. M.; Habetler, T. G. \& Harley, R. G. (2003). Stator winding turn-fault detection for closed-loop induction motor drives, IEEE Transactions on Industry Applications, vol. 39, no. 3, pp. 720-724.

Tallam, R. M.; Lee, S. B.; Stone, G. C.; Kliman, G. B.; Yoo, J.; Habetler, T. G. \& Harley, R. G. (2007). A Survey of Methods for Detection of Stator-Related Faults in Induction Machines, IEEE Transactions on Industry Applications, vol. 43, no. 4, pp. 920-933.

Thomson, W. T. \& Ranking, D. (1987). Case History of Rotor Winding Fault Diagnosis in Induction Motors, Conference Proceedings of Condition Monitoring, University College Swanse, 798-819.

Thomson, W. T. \& Fenger, M. (2001). Current Signature Analysis to Detect Induction Motor Faults, IEEE Industry Applications Magazine, vol. 7, no. 4, pp. 26-34.

Wieser, R.; Kral, C.; Pirker, F. \& Schagginger, M. (1999). On-Line Rotor Cage Monitoring of Inverter-Fed Induction Machines by Means of an Improved Method, IEEE Transactions on Power Electronics, vol. 14, no. 5, pp. 858-865.

Wolbank, T. M.; Loparo, K. A. \& Wohrnschimmel, R. (2003). Inverter statistics for online detection of stator asymmetries in inverter-fed induction motors, IEEE Transactions on Industry Applications, no. 39, vol. 4, pp. 1102-1108.

Wu, L.; Habetler, T. \& Harley, R. (2005). Separating Load Torque Oscillation and Rotor Fault Effects in Stator Current-Based Motor Condition Monitoring, IEEE, International Electric Machines and Drives Conference, 1889-1894.

$\mathrm{Wu}$, Y. \& Gao, H. (2006). Induction-motor stator and rotor winding temperature estimation using signal injection method, IEEE Transactions on Industry Applications, vol. 43, no. 4, pp. 1038-1044.

Wu, L.; Habetler, T. \& Harley, R. (2007). A Review of Separating Mechanical Load Effects from Rotor Faults Detection in Induction Motors, IEEE International Symposium on Diagnostics for Electric Machines, Power Electronics and Drives, The 6th, SDEMPED 2007, Cracow, Poland.

B. Yazici and G. B. Kliman, (1999). An adaptive statistical time-frequency method for detection of broken bars and bearing faults in motors using stator current, IEEE Trans. Industry Applications, vol. 35, no. 2, pp. 442-452.

Zhang, P.; Lu, B. \& Habetler, T. G. (2008). A Remote and Sensorless Stator Winding Resistance Estimation Method for Thermal Protection of Soft-Starter-Connected Induction Machines, IEEE Transactions on Industrial Electronics, vol. 55, no. 10, pp. 3611-3618.

Zhao Y.; Atlas, L. E.; Marks II, R. J. (1990). The use of cone-shaped kernels for generalized timefrequency representations of nonstationary signals, IEEE Trans. on Acoustics, Speech, and Signal Processing, vol. 38, no. 7, pp. 1084-1091. 


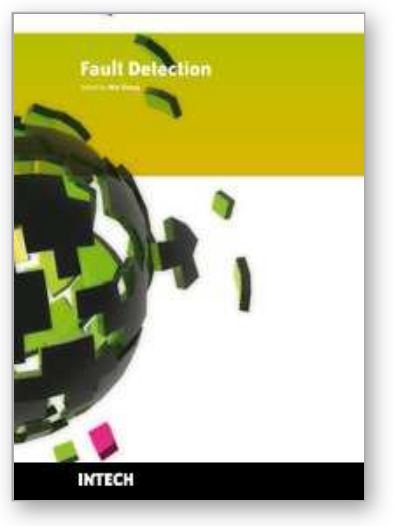

\author{
Fault Detection \\ Edited by Wei Zhang
}

ISBN 978-953-307-037-7

Hard cover, 504 pages

Publisher InTech

Published online 01, March, 2010

Published in print edition March, 2010

In this book, a number of innovative fault diagnosis algorithms in recently years are introduced. These methods can detect failures of various types of system effectively, and with a relatively high significance.

\title{
How to reference
}

In order to correctly reference this scholarly work, feel free to copy and paste the following:

Christian Kral and Thomas G. Habetler (2010). Condition Monitoring and Fault Detection of Electric Drives, Fault Detection, Wei Zhang (Ed.), ISBN: 978-953-307-037-7, InTech, Available from:

http://www.intechopen.com/books/fault-detection/condition-monitoring-and-fault-detection-of-electric-drives

\section{INTECH}

open science | open minds

\section{InTech Europe}

University Campus STeP Ri

Slavka Krautzeka 83/A

51000 Rijeka, Croatia

Phone: +385 (51) 770447

Fax: +385 (51) 686166

www.intechopen.com

\section{InTech China}

Unit 405, Office Block, Hotel Equatorial Shanghai

No.65, Yan An Road (West), Shanghai, 200040, China

中国上海市延安西路65号上海国际贵都大饭店办公楼 405 单元

Phone: +86-21-62489820

Fax: +86-21-62489821 
(C) 2010 The Author(s). Licensee IntechOpen. This chapter is distributed under the terms of the Creative Commons Attribution-NonCommercialShareAlike-3.0 License, which permits use, distribution and reproduction for non-commercial purposes, provided the original is properly cited and derivative works building on this content are distributed under the same license. 